\title{
ERRATUM
}

\section{Chapter 8 \\ Functional Nanoparticles for Molecular Imaging-Guided Gene Delivery and Therapy}

\author{
Tianxin Miao, Yu Zhang, Yun Zeng, Rui Tian, and Gang Liu
}

(C) Springer Science+Business Media Singapore 2016

Z. Dai (ed.), Advances in Nanotheranostics II, Springer Series

in Biomaterials Science and Engineering 7, DOI 10.1007/978-981-10-0063-8

DOI 10.1007/978-981-10-0063-8_11

In Chapter 8 titled "Functional Nanoparticles for Molecular Imaging-Guided Gene Delivery and Therapy", the name and affiliation of the author Yu Zhang was incorrect.

In the List of Contributors in the FM, the name and affiliation of Yu Zhang has been missed.

The author name and correct affiliation should read as follows:

Y. Zhang

Electrical Engineering Program, College of Engineering and Mathematical Sciences, University of Vermont, Burlington, VT 05405, USA 